\title{
The Development of Realistic Mathematics Education (RME) For Primary Schools' Prospective Teachers
}

\author{
Wahyudi $^{1}$, Joharman ${ }^{1}$, Ngatman $^{1}$ \\ ${ }^{1}$ Primary Teacher Education Program, Teacher Training and Education Faculty, Sebelas Maret \\ University \\ Email: wahyudi@fkip.uns.ac.id
}

\begin{abstract}
This research mainly focuses on: (1) the development of Realistic Mathematics Education (RME), (2) improving the effectiveness of Mathematics learning with the application of RME, and (3) constraints and solutions in the implementation of RME for primary schools prospective teachers. This research was conducted in the Primary Teacher Education Program of Teacher Training and Education Faculty of Sebelas Maret University, using the Research and Development (R \& D) and implementing Classroom Action Research (CAR). The research subject included 71 students attending Basic Mathematics II in Academic Years 2015/2016. Data were validated using data and methodological triangulations. Afterwards, they were analyzed using qualitative analysis comprising three streams of activities: data reduction, data display, and conclusion drawing. Research procedure used was CAR with series of cycles involving such steps as (1) planning, (2) action, (3) observing, and (4) reflecting which was conducted simultaneously.The research finds out that: (1) Five steps of the implementation of RME for prospective teachers of primary school are (a) understanding daily problem/ context, (b) explaining contextual problem, (c) solving contextual problems, (d) comparing and discussing answers, and (e) drawing conclusion. (2) The implementation of RME can improve the effectiveness of Mathematics learning, (3) constraints in the implementation of RME include: (a) students do not have adequate understanding on Mathematics teaching materials, (b) students are not familiar enough with problems in learning Mathematics related to problems in daily life, (c) students are not quite familiar with the usage of teaching media in Mathematics learning, (d) students do not well master various approaches in Mathematics learning, (e) students do not acquire skill well in arranging lesson plans for Mathematics learning, and (f) students are not skilled enough in the simulation of Mathematics learning. Meanwhile, solutions for the difficulties are reinforcement and assistance in: (1) the mastery of teaching materials, (2) the relationship between teaching materials and problems in daily life, (3) uses of media/visual aids for Mathematics learning, (4) the mastery of various approaches and methods in Mathematics learning, (5) the arrangement of lesson plans in Mathematics learning, and (6) simulation of Mathematics learning.
\end{abstract}

Keywords: Realistic; Mathematics; Education; Primary School 


\section{INTRODUCTION}

National Education of Indonesia aims at the development of the potential of learners to become human beings who believe and cautious to God Almighty, have a noble character, healthy, knowledgeable, capable, creative, independent, and become a democratic and responsible citizens (Article 3, Law No 20 of 2003 on National Education System).

Teachers have the duty and the obligation to realize the goals of education in their own schools. This can be seen in Law No. 14 of 2005 on Teachers and Lecturers that "the position of teachers and lecturers as professionals aims to implement the national education system and realize the goals of national education ......". One of the main tasks of teachers is to create an environment and learning environment that supports for learners. Solutions that can be done, among others, by the use of learning approaches in each learning with the aim of helping smoothness, effectiveness, and efficiency in achieving educational goals.

Selection of the right learning approach will make learning fun. This is because students seem to play, so the result will be more meaningful because students get involved in it. Therefore, to improve students' understanding of the concepts to be taught, teachers should use appropriate learning approaches on every subject including Mathematics.

As a prospective primary school teacher who will become a classroom teacher, where a teacher will teach at all grade levels and all subjects, the Primary School Teacher Education Study Program will equip students with a comprehensive curriculum that can produce competent and professional teacher candidates. In connection with the Mathematics course in the curriculum of Primary School Teacher Education Study Program, Faculty of Teacher Training and Education, Sebelas Maret University of Surakarta, there are four courses that must be taken by Primary School teacher candidates, namely (1) Basic Mathematics Concept 1, (2) Basic Mathematics Concept 2, (3) Primary School Mathematics Education 1, and (4) Primary School Mathematics Education 2.

In order for teacher competence and qualifications to be achieved, the Primary School Teacher Education Study Program, Faculty of Teacher Training and Education, Sebelas Maret University of Surakarta as one of the universities that organizes the Primary School Teacher Education program, strives to produce a competent and professional Primary School teacher candidate. Therefore, the learning process both inside and outside the classroom must be systematically and professionally managed. In order for the learning process to be well organized, it is necessary to master the concepts and approaches or effective learning strategies.

For more than twenty years, the mathematics education in the Netherlands has had many changes, shifting from the mechanistic and sometimes structuralistic to the so-called 'realistic' approach to primary and secondary education. According to mechanistic view, mathematics is a system of rules and algorithms. The emphasis of this view is on verifying and applying rules for problems similar to the previous problem. Much attention is spent on gradual approaches of caution, memorization, and learning 'tricks'. In structuralistic view [1], mathematics is seen as a cognitive achievement organized by a deductive system, and the learning process in mathematics education must be guided by the structure of this system. 
Realistic Mathematics Education in the Netherlands begins at a completely different point from previous views, and aims to construct knowledge by children based on their own mathematical knowledge by giving meaning to real-world context issues [2,3]. In this approach, students are challenged to develop their own strategies to solve the problem, and to discuss with other students. Finding solutions to realworld problems is not the end of the math lesson in this approach. Teachers help students to develop their informal strategies into a more formal approach, then it can be used in other situations [3]. As Freudenthal [2] states, it reflects the shift from mathematics as a created subject (made by others, especially mathematics) to mathematics as the subject to be made. This means more dynamic mathematics. Mathematical action and the process of developing a strategy get more attention than static and disconnected knowledge. Freudenthal [4] stresses that in this approach the child will be given the opportunity to "reinvent" mathematical ideas.

The consequence of a 'realistic turn' in mathematics education is that teachers should be prepared with curriculum goals that are very different from the curriculum they experience themselves when they become students. Although in class practice, traditional mathematics rarely found in the Netherlands, there are data reflecting the very didactic nature of these practices. Tomic [5], for example, points out that in math lessons high school students spend only $11 \%$ in talking with teachers, $22 \%$ of their time doing self-employment, and $51 \%$ of their time listening or doing homework.

Evaluative research has been conducted on this teacher education program. Therefore, one of the first things that needs to be built is reflection and promotion, both in mathematical components and professional preparation [6-8]. Although the focus of the research program has changed, the results of this study still seem important for other efforts in teacher education to promote changes in mathematics teacher conceptions and learning as well as mathematics teaching.

Realistic Mathematics Education (RME) is an approach in mathematics education which was first introduced and developed in 1971 by a group of mathematicians from Freudenthal Institute of Utrecht University of the Netherlands. The approach is based on Hans Freudenthal's (1905-1990) view that mathematics is human activity. Mathematics class is not considered as a place to transfer knowledge of Mathematics from a teacher to students, but rather a place where students can reinvent mathematical ideas and concepts through exploration of real problems. Mathematics is regarded as human activity which begins with problem solving. The students should not be considered passive recipients, but rather they should be given a chance to reinvent mathematical ideas and concepts under the guidance of their lecturer. The reinvention is developed through the learning of various real daily-life problem situations. Real life is defined as anything beyond mathematics, such as daily life, surrounding environment, even other subjects. It is used as a starting point of the mathematics learning. To prove that a process is more important than an outcome, a term 'mathematization' is used in RME to refer to a mathematizing process of realistic contexts. It is illustrated by de Lange [9] as an endless circle. A realistic approach is an approach that uses realistic problems as the starting point of mathematics learning based on the idea that mathematics is a human activity and that mathematics must be linked significantly to the context of everyday life of the student as a source of development and as an application area through a process of mathematization. The foregoing can be accomplished if the learning process using 
Realistic Mathematics Education, namely an approach in which mathematics class is not considered as a place to transfer knowledge of mathematics from a teacher to students, but rather a place where students can reinvent mathematical ideas and concepts through exploration of real problems. Here, Mathematics is regarded as human activity which begins with problem solving [10]. A typical example of a realistic mathematical problem is tracing from ongoing changes to the number of bus passengers at a bus stop [11]. In situations of passengers entering and leaving the bus, the process of addition and subtraction arises in a natural way. Therefore, the problems presented above illustrate only part of the realistic mathematics education. In the realistic mathematics education, formalization stage reached in successive stages. To understand more detailed principles in curriculum materials, it takes at least a month to explain [9].

Many researchers claim that teaching strategies used to teach a subject for prospective teachers have a strong influence on their conception of topics and teaching and learning processes [12-15]. Stofflett and Stoddart [16], for example, have shown that prospective teachers who have active learning are more likely to plan active lessons and facilitate active knowledge construction.

Gravemeijer [11] (1994: 82) states that RME is rooted in Freudenthal's interpretation of mathematics as human activity. Freudenthal takes his starting point in the activity of mathematicians, whether pure or applied. He characterizes their activity as an activity of solving problems, looking for problems, and organizing subject matter-whether it belongs to mathematical matter or matter from reality. According to Freudenthal, the latter activity — organizing or mathematizing — serves as the main activity. Interestingly, he sees it as a general activity which represents typical characteristics of both pure and applied mathematics. Consequently, when setting 'mathematizing' as a goal for mathematics education, it can cover mathematizing mathematics and mathematizing reality. Gravemeijer [11] mentions three main principles in RME:

The first principle is termed "guided reinvention" and progressive mathematizing. According to the reinvention principle, the students should be given the opportunity to experience a process similiar to the process by which mathematics was invented.

The second principle relates to the idea of a dedactical phenomenology. According to a dedactical phenomenology, situations where a given mathematical topic is applied are to be investigated for two reasons. Firstly, to reveal the kind of applications that have to be anticipated in intruction, secondly, to consider their suitability as points of impact for process of progressive mathematization.

The third principle is found in the role which self-developed models play in bridging the gap between information knowladge and formal mathematics.

According to Gravemeijer [11] RME has five characteristics as follows:

(1) The use of real world context

Realistic mathematics education emphasizes the importance of exploring the phenomena of everyday life. The informal knowledge that students gain from everyday life is used as a contextual problem to be developed into a formal mathematical concept.

(2) Vertical instrument (the use of models)

The development of informal knowledge of students into formal concepts of mathematics is a gradual process. The process can be supported with the use of 
models and symbols. The use of models is a bridge for students to create their own models from real situations to abstracts or from informal to formal situations.

(3) Students' contribution (the use of production and construction)

Students actively construct their own mathematical materials based on facilities with the learning environment provided by teachers, actively solving problems in their own way.

(4) Interactive activity (the use of interactivity)

Interaction between students with teachers, students with students, and students with learning tools is important in Realistic mathematics education. Consequently, interactive learning activities will enable communication, negotiation, explanation, ask and respond to questions and reflections to achieve form of formal knowledge.

(5) Topic relatedness (the use of relatedness)

The learning of a mathematical material is related to various mathematical topics in an integrated manner. Mathematical structures and concepts are interrelated, usually a topic discussion should be explored to support meaningful learning.

A few things to note from the characteristics of the approach to Realistic Mathematics Education above are RME belongs to:

a) 'active students' way of learning' since the mathematics learning is conducted by 'learning by doing';

b) student-centered learning since the students solve their problem themselves according to their ability - in this case, their teacher merely serves as a facilitator;

c) guided inquiry-based learning since the students are required to invent and reinvent mathematical concepts and principles;

d) contextual learning since the starting point of mathematic learning is contextual matter-which includes students' problem in their everyday life;

e) constructivist learning since the students are guided to reinvent their knowledge of mathematics by themselves by solving problem and discussing.

From the above explanation, it is assumed that in principle, the realistic mathematical approach is a combination of constructivism and contextual approaches, in the sense of giving students the opportunity to construct their own understanding of mathematical ideas and concepts through the solving of real-world problems (contextual).

One consequence of the above mentioned principles is that the role of the teacher is to facilitate learning, not just transmitting knowledge. Treffers [3] states that in realistic mathematics, teacher education must use student construction to help them build new constructions, solve problems and others. For teacher education, this step is an important part of facilitating their role in working as prospective teachers.

This article focuses on the problem (1) the development of Realistic Mathematics Education (RME), (2) the improvement of learning effectiveness using the implementation of RME, and (3) constraints and solutions in the implementation of RME. 


\section{RESEARCH METHOD}

The research was conducted in the academic year 2015/2016 using the Research and Development (R \& D) and Classroom Action Research (CAR with series of cycle) to produce the RME Learning Model. This Research and Development Procedure summarizes Borg and Gall [17] concept consisting of 10 stages into 4 stages [18], namely (1) prototype preparation stage, covering (a) literature study, (b) exploration study, (c) needs identification, (d) needs analysis (e) description of findings, (f) prototype design, and (g) prototype workshop; (2) prototype development, includes (a) expert assessment, (b) limited and revised trials, (c) broad and revised trials, and (d) new model products; (3) the testing phase, which is to test the effectiveness of the developed model; and (4) the phase of dissemination and publication.

Classroom Action Research (CAR with series of cycle) was utilized as research procedure in this research. It comprises three cycles, each of which covers three meetings. Each cycle simultaneously involves four steps: (1) planning, (2) action, (3) observing, and (4) reflecting [19].

In the planning step, the researcher identifies and formulates problems based on a preliminary study. Furthermore, the researcher develops the learning scenario based on Realistic Mathematics Education characteristics, then the researcher develops the lesson plan with realistic mathematical approach. In addition, researcher also prepares learning tools and research instruments in the form of learning media, observation sheets, and learning evaluation tools.

In the implementation step, the researcher conducts the learning activities using Realistic Mathematics Education in accordance with the plan that has been prepared. After that, researchers began to engage in core activities. Researchers explain learning materials using Realistic Mathematics Education steps. After the students finished studying with Realistic Mathematics Education, the students together with the researcher concluded the learning materials. The last step in this cycle is marked by the evaluation of learning outcomes in the form of post test that must be done by students individually. This is useful for measuring the extent to which success rates are achieved in the implementation of the action.

In the observation step, the researcher cooperates with colleagues involving two lecturers of Mathematics as a collaborator to become an observer. During the activity, the observer observed the learning process by filling out the observation sheet of Realistic Mathematics Education provided by the researcher. Obviously, researchers also observed the process of learning directly in addition to the task of implementing actions in the form of learning with Realistic Mathematics Education approach.

In the reflection step, the researcher analyzes the process and the result of learning evaluation using Realistic Mathematics Education, and analyzes the observation result of the learning implementation, and then concludes the implementation of the action as the basis for determining the follow-up activities. If the next cycle is required, the researcher immediately prepares the next action, with the same stages as the previous cycle. This is done repeatedly, to find valid conclusions about the process and learning outcomes by using Realistic Mathematics Education, in accordance with research objectives. 
This research use research subject as research participant, that is all student of Primary School Teacher Education Faculty of Teacher Training and Education, Sebelas Maret University who take subject of Primary School Mathematics Education 2 as much as 71 students. They graduated from high school or vocational high schools, who do not have an in-depth knowledge of Mathematics education and learning. Pedagogic knowledge has just learned in the first and second semester.

Techniques of collecting data used are observation, tests, and interviews. Observation of the researcher was conducted by colleagues at the time of implementing learning with Realistic Mathematics Education based on learning scenarios that have been prepared. In addition, observation results are also used to find constraints and solutions for the implementation of Realistic Mathematics Education. The test technique is used to collect data about student learning outcomes about Mathematics Education taught by using Realistic Mathematics Education. The form of the test is a description test prepared by the researcher, to reveal the process and the results of mathematics learning. Interviews were conducted to collect data from students, peers to reinforce the conclusions to be taken with regard to the application of Realistic Mathematics Education. Interview techniques are used to obtain conscious ideas, experiences and opinions from respondents. For this reason, open-ended questions about the learning process with Realistic Mathematics Education are used. Interview results were analyzed using an inductive strategy ${ }^{[20]}$.

Data analysis used in this research is quantitative and qualitative data analysis. Quantitative data in the form of data of learning result of Primary School Mathematics Education 2 which is obtained after applying Realistic Mathematics Education model. The analysis used in the data is a comparison analysis between meetings and between cycles. While the qualitative data in the form of observations and interviews about the implementation of learning by applying Realistic Mathematics Education model. These data were analyzed qualitatively, which consisted of three sequences of activities performed simultaneously and continuously during and after data collection ie data reduction, data presentation, and conclusion or verification [21].

\section{RESULT AND DISCUSSION}

\section{The Development of Realistic Mathematic Education (RME)}

Based on the characteristics of Realistic Mathematic Education (RME), then the learning steps based on RME are developed as a guide for learning Mathematics. Learning guides are arranged in the form of learning scenarios, namely in the form of activities that provide direction for lecturers and students in the implementation of learning with RME. The learning steps and activities that must be implemented by lecturers and students in the application of Realistic Mathematics Education are as follows:

1. Understanding daily problem/context.

Lecturers provide contextual problems and ask students to understand the problem. This step is characteristic 1 of RME, that is understanding daily problem/ context. 
Several activities in this stage are: (a) creating a classroom atmosphere for learning activities, (b) explaining learning objectives intended to achieve, (c) starting the learning by providing examples of problems in everyday life, (d) demonstrating the problem solving using suitable audio-visual aids, and (e) providing questions about problem solving which are frequently found in real life.

2. Explaining contextual problem.

The second step is implemented if there are students who do not understand the problem given. If all students have understood then this step is no longer needed. In this step, the lecturer explains the situation and condition of the problem by giving the necessary instructions to certain parts that have not been used by the students. This step is characteristic 4 of RME, that is the interactive activity, interaction between students with teachers and students with other students.

Explaining contextual problem includes activity of: (a) preparing discussion forum, (b) explaining the discussion procedures, (c) assigning discussion, (d) preparing media/ audio-visual aids, (e) conducting the discussion, (f) relating data with concepts, $(\mathrm{g})$ revealing the answers of the questions related to problems, (h) discussing and revealing information of problems in learning.

3. Solving contextual problems.

Students solve problems in groups or individuals. In solving the problem, students are allowed to use different ways. Using the activity sheet, students work on the problem and solve problems in different difficulty levels. Lecturers motivate students to solve problems in their own way by providing direction in the form of questions and motivation. This step is characteristic 2 and 5 of RME, ie vertical instrument (the use of the model) and Topic relatedness (the use of relatedness). Solving contextual problems including some activities: (a) directing students to prepare visual aids in coping with learning problems, (b) guiding students in using visual aids to solve problems in learning, and (c) guiding students to prepare learning models using appropriate visual aids.

4. Comparing and discussing answers.

Lecturers facilitate discussion and provide time to compare and discuss answers to problems in groups, and then class discussions are held. This step is characteristic 3 and 4 of RME that is using students' contribution and interaction among students with one another. This stage includes the following activities: (a) providing students with guidelines to solve problems in mathematics learning based on their own experiences, (b) monitoring students' activities when solving problems/doing tasks periodically, (c) presenting working results in mathematics learning consecutively in class, (d) the lecturer serves as moderator and facilitator in class discussion, (e) together with students, giving responses to presentation result in class discussion forum, (f) together with students, making a reflection on the results of their presentation in mathematics learning, and (g) concluding the results of presentation and class discussion.

5. Drawing conclusion.

From the results of class discussions, the lecturer asks students to draw conclusions of a concept, then summarizes or completes the concepts contained in the problem solving. This stage comprises several activities: (a) students analyze mathematics curriculum at primary school, (b) students arrange competencies that have to be mastered by prmary school students in mathematics learning, (c) students arrange lesson plans for mathematics learning for primary school 
students, (d) students implement the lesson plans in peer teaching, (e) students perform class discussion and reflection towards the lesson plans that have been practiced in peer teaching, (f) students provide feedbacks for lesson plans that have been practiced, and (g) students draw conclusion on lesson plans that have been composed and practiced.

Based on the activities contained in each learning step with Realistic Mathematics Education, it is also used to arrange the observation instrument of learning with RME. After all learning tools are prepared, the learning process with Realistic Mathematics Education can be implemented.

\section{Implementation of Realistic Mathematic Education (RME)}

To obtain data about mathematics learning with Realistic Mathematics Education approach in accordance with the steps that have been compiled, it is necessary to run a preliminary test of implementing mathematics learning with RME approach. This preliminary test was carried out for three cycles. Each cycle consists of three meetings. Therefore, the test of mathematics learning with RME approach was conducted for 9 meetings in the form of lectures in accordance with the fixed schedule of mathematics education for elementary school.

The result of observation on the implementation of learning conducted by lecturers and students for three cycles is presented in table 1, table 2, and table 3 below.

TABLE I: OBSERVATION RESULTS OF THE IMPLEMENTATION OF LEARNING USING RME (LECTURER'S ACTIVITIES) IN CYCLE I, II, AND III

\begin{tabular}{|llcccc|}
\hline \multirow{2}{*}{ No } & & \multicolumn{3}{c}{$\begin{array}{c}\text { Mean Score } \\
\text { Observation of RME }\end{array}$} & \\
\cline { 3 - 5 } & & CycleI & CycleII & CycleII & \\
& & & & I & \\
\hline 1 & Understanding daily problem/ context & 3.65 & 3.75 & 3.85 & $\mathbf{3 . 7 5}$ \\
2 & Explaining contextual problem & 3.60 & 3.80 & 3.83 & $\mathbf{3 . 7 4}$ \\
3 & Solving contextual problems & 3.60 & 3.70 & 3.83 & $\mathbf{3 . 7 1}$ \\
4 & Comparing and discussing answers & 3.70 & 3.80 & 3.82 & $\mathbf{3 . 7 7}$ \\
5 & Drawing conclusion & 3.65 & 3.75 & 3.85 & $\mathbf{3 . 7 5}$ \\
& Average & $\mathbf{3 . 6 4}$ & $\mathbf{3 . 7 6}$ & $\mathbf{3 . 8 4}$ & $\mathbf{3 . 7 5}$ \\
\hline
\end{tabular}

Note: Score of $1=$ Poor, 2 = Fair, $3=$ Good, $4=$ Excellent

TABLE II: OBSERVATION RESULTS OF THE IMPLEMENTATION OF LEARNING USING RME (STUDENTS' ACTIVITIES) IN CYCLE I, II, AND III

\begin{tabular}{|llcccc|}
\hline No & \multirow{2}{*}{ RME Steps } & \multicolumn{3}{c}{ Mean Score } & \multirow{2}{*}{ Average } \\
\cline { 3 - 5 } & & & Observation of RME & \\
& & & & & \\
& & 3.65 & 3.70 & 3.85 & $\mathbf{3 . 7 3}$ \\
& & 3.60 & 3.70 & 3.85 & $\mathbf{3 . 7 2}$ \\
\hline 1 & Understanding daily problem/ context & 3.50 & 3.75 & 3.80 & $\mathbf{3 . 6 8}$ \\
3 & Explaining contextual problem & 3.65 & 3.80 & 3.83 & $\mathbf{3 . 7 6}$ \\
3 & Solving contextual problems & 3.65 & 3.75 & 3.85 & $\mathbf{3 . 7 5}$ \\
4 & Comparing and discussing answers & $\mathbf{3 . 6 1}$ & $\mathbf{3 . 7 4}$ & $\mathbf{3 . 8 4}$ & $\mathbf{3 . 7 3}$ \\
5 & Drawing conclusion & & & &
\end{tabular}

Note: Score of 1 = Poor, 2 = Fair, 3 = Good, 4 = Excellent 
Based on the observation, the learning steps using Realistic Mathematics Education model are (1) understanding daily problem/ context, (2) explaining contextual problem, (3) solving contextual problems, (4) comparing and discussing answers, and (5) drawing conclusion. From the five learning steps of RME in Cycle I, the average score of the first step, understanding daily problem/ context, is 3.65. This happens because the students have noticed the learning objectives to be achieved. Similarly, step 2, 3, 4, and 5 obtained an average score of 3.61. As in the lecturer activity in cycle I has obtained an average score of 3.64. This means that learning has proceeded according to plan. In cycle II, from the five steps of learning RME, steps 1, 2, 3, 4 and 5 obtained an average score of 3.74 for student activities and lecturer activities obtained an average score of 3.76. This means that learning has proceeded according to plan. Meanwhile, in cycle III, from the five steps of learning RME, steps 1, 2, 3, 4 and 5 obtained an average score of 3.84 for student activities and lecturer activities obtained an average score of 3.84 .

TABLE III: LEARNING OUTCOMES USING RME IN CYCLE I, II, III

\begin{tabular}{|ccccc|}
\hline Score & \multicolumn{3}{c|}{ Post-test } & Note(s) \\
\cline { 2 - 4 } & Cycle I & Cycle II & Cycle III & Passed \\
$60-69$ & 0 & 5 & 2 & Passed \\
$70-79$ & 67 & 16 & 10 & Passed \\
$80-89$ & 4 & 40 & 51 & Passed \\
$90-100$ & 0 & 10 & 8 & \\
Total & 71 & 71 & 71 & \\
Average & $\mathbf{7 2 . 5 8}$ & $\mathbf{8 0 . 3 9}$ & $\mathbf{8 2 . 4 4}$ & \\
Lowest Score & $\mathbf{7 0}$ & $\mathbf{6 0}$ & $\mathbf{6 5}$ & \\
Highest Score & $\mathbf{8 0}$ & $\mathbf{9 5}$ & $\mathbf{9 5}$ & \\
Completeness (\%) & $\mathbf{1 0 0}$ & $\mathbf{1 0 0}$ & $\mathbf{1 0 0}$ & \\
\hline
\end{tabular}

Based on the above data, in cycle I, from 71 students, there are 71 students $(100 \%)$ who completely master the competence and there were no students who failed. The lowest and highest score were 70 and 80 . The average score of post-test was 72.58. And then, in cycle II, from 71 students, there are 71 students (100\%) who completely master the competence and there were no students who failed. The lowest and highest score were 60 and 95. The average score of post-test was 80.39. In cycle III, from 71 students, there are 71 students (100\%) who completely master the competence and there were no students who failed. The lowest and highest score were 65 and 95. The average score of post-test was 82.44. This indicates that there was a significant improvement of learning outcomes in each cycle by the implementation of Realistic Mathematic Education.

\section{Constrains and Solutions in the Implementation of Realistic Mathematic Education (RME)}

On the basis of learning implementation using Realistic Mathematics Education (RME) comprising 2 cycles, constraints in the development of Realistic Mathematics Education (RME) for the improvement of mathematics learning of students, namely (1) students do not have adequate understanding on mathematics teaching materials for primary school, (2) students are not familiar enough with problems in learning mathematics related to in daily life, (3) students are not quite familiar with the usage of teaching media/visual aids in mathematics learning, (4) students do 
not master various approaches in mathematics learning well, (5) students do not acquire skill well in arranging lesson plans for mathematics learning in primary school, (6) students are not skilled enough in the simulation of mathematics learning in primary school. Solutions for those problems are (1) reinforcing the mastery of teaching materials and mathematical concepts in primary school, (2) reinforcing the relationship between teaching materials and problems in daily life, (3) reinforcing identification and usage of media/visual aids for mathematics learning in primary school, (4) reinforcing the mastery of various approaches in mathematics learning in primary school, (5) reinforcing the arrangement of lesson plans, and (6) reinforcing simulation of mathematics learning in primary school.

\section{CONCLUSION}

On the basis of research problems and the results of research data analysis in cycle 1, 2, and 3, conclusion can be drawn as the followings: (1) Realistic Mathematics Education (RME) is done through 5 steps: (1) understanding problems/contexts in daily life, (2) explaining contextual problems, (3) solving contextual problems, (4) comparing and discussing answers, and (5) drawing conclusion. (2) Realistic Mathematics Education (RME) can improve the learning effectiveness for the prospective teachers of primary schools, (3) Realistic Mathematics Education (RME) faces some obstacles, including: (1) students do not have adequate understanding on mathematics teaching materials for primary school, (2) students are not familiar enough with problems in learning mathematics related to problems in daily life, (3) students are not quite familiar with the usage of teaching media/visual aids in mathematics learning, (4) students do not well master various approaches in mathematics learning, (5) students do not acquire skill well in arranging lesson plans for mathematics learning in primary school, and (6) students are not skilled enough in the simulation of mathematics learning in primary school. Solutions for the difficulties comprise: (1) reinforcing the mastery of teaching materials and mathematical concepts in primary school, (2) reinforcing the relationship between teaching materials and problems in daily life, (3) reinforcing identification and uses of media/visual aids for mathematics learning in primary school, (4) reinforcing the mastery of various approaches in mathematics learning in primary school, (5) reinforcing the arrangement of lesson plans, and (6) reinforcing simulation of mathematics learning in primary school.

\section{REFERENCES}

[1] Dieudonn'e, J.: 1982, 'The work of Bourbaki during the last thirty years', Bulletin of the American Mathematical Society 29, 618-623.

[2] Freudenthal, H.: 1978, Weeding and Sowing. Preface of a Science of Mathematics Education. Reidel. Publishing Company, Dordrecht.

[3] Treffers, A.: 1987, 'Three Dimensions', A Model of Goals and Theory Description in Mathematics Instruction - TheWiskobas Project,Reidel Publishing Company, Dordrecht.

[4] Freudenthal, H.: 1991, Revisiting Mathematics Education: China Lectures, Kluwer, Dordrecht/Boston/London.

[5] Tomic, W.: 1985, Docentengedrag en leerresultaten, Grafoplan, Enschede. 
[6] Korthagen, F. A. J.: 1985, 'Reflective teaching and pre-service teacher education in the Netherlands', Journal of Teacher Education 36, (5), 11-15.

[7] Korthagen, F. A. J.: 1988, 'The influence of learning orientations on the development of reflective teaching'. In J. Calderhead (ed.), Teachers'

[8] Korthagen, F. A. J. and Wubbels, Th.: 1995, 'Characteristics of Reflective Practioners: towards an operationalization of the concept of reflection', Teachers and Teaching: Theory and Practice 1, 1, 51-72.

[9] De Lange Jzn, J.: 1987, Mathematics Insight and Meaning, OW\&OC, Utrecht.

[10] Dolk, Maarten. 2006. Realistik Mathematics Education. Makalah Kuliah Umum di Program Pasca Sarjana Universitas Sriwijaya Palembang, Tanggal 29 Juli 2006

[11] Gravemeijer, K. P. E.: 1994, Developing Realistic Mathematics Evaluation, CDB Press, Utrecht.

[12] Kagan, D. M.: 1992, 'Professional growth among pre-service and beginning teachers', Review of Educational Research 62 (2), 129-169.

[13] Lortie, D.: 1975, Schoolteacher: A sociological Study, University of Chicago Press, Chicago.

[14] Thompson, A. G.: 1984, 'The relationship of teachers' conceptions of mathematics and mathematics teaching to instructional practice', Educational Studies in Mathematics 15, 105-127.

[15] Huibregtse, I., Korthagen, F. and Wubbels, Th.: 1994, 'Physics teachers' conceptions of learning, teaching and professional development', International Journal of Science Education 16, 5, 539-561.

[16] Stofflett, R. T. and Stoddart, T.: 1994, 'The ability to understand and use conceptual change pedagogy as a function of prior content learning experience', Journal of Research in Science Teaching 31, (1), 31-51.

[17] Borg, W.R. and Gall, M.D. 2003. Educational Research. Boston: Pearson Education. Inc

[18] Sugiyono. 2013. Metode Penelitiarn Kualitatif, Kuantitatif, dan $R \& D$. Bandung: CV Alfabeta.

[19] Hopkins, D. 1993. A Teacher's Guide to Classroom Research. Buckingham: Open University Press.

[20] Glaser, B. G., \& Strauss A. L.: 1967, The Discovery of Grounded Theory: Strategies for Qualitative Research, Aldine, Chicago.

[21] Rohendi Rohidi, T. 1992. Analisis Data Kualitatif: Terjemehan: Qualitative Data Analysis (Mathew B. Miles dan A. Michael Huberman). Jakarta: Penerbit UI Press.

[22] Dolk, M., Korthagen, F. A. J., and Wubbels, Th.: 1995, What Makes Teachers Teach theWay They Teach? Instruments to Investigate Aspects of Teacher's Gestalts. Paper presented at the 6th European Conference for Research on Learning and Instruction. Nijmegen, The Netherlands.

[23] Heuvel, M. Van den; Panhuizen. 1996. Assesment and Realistic Mathematics Education. Nederlands: Fruedental institute.

[24] Professional Learning, Falmer Press, London, pp. 35-50.

[25] Korthagen, F. A. J.: 1993, 'Two modes of reflection', Teaching \& Teacher Education 9, (3), 317-326. 
[26] Pratt, D. D.: 1988, 'Andragogy as a relational construct', Adult Education Ouarterly 38 (3), 160-172.

[27] Van den Brink, F. J.: 1984, 'Numbers in contextual frameworks', Educational Studies in Mathematics 15, 239-257.

[28] Wubbels, Th., and Korthagen F. A. J.: 1990, 'The effects of a pre-service teacher education program for the preparation of reflective teachers', Journal of Education for Teaching 16, (1), 29-43.

[29] Wubbels, Th.: 1992, 'Taking account of student teacher's preconceptions', Teaching and Teacher Education 8, (2), 137-149.

[30] Wubbels, Th., and J. Levy: 1993, Do You Know What You Look Like? Interpersonal Relations in the Classroom, Falmer Press, London. 